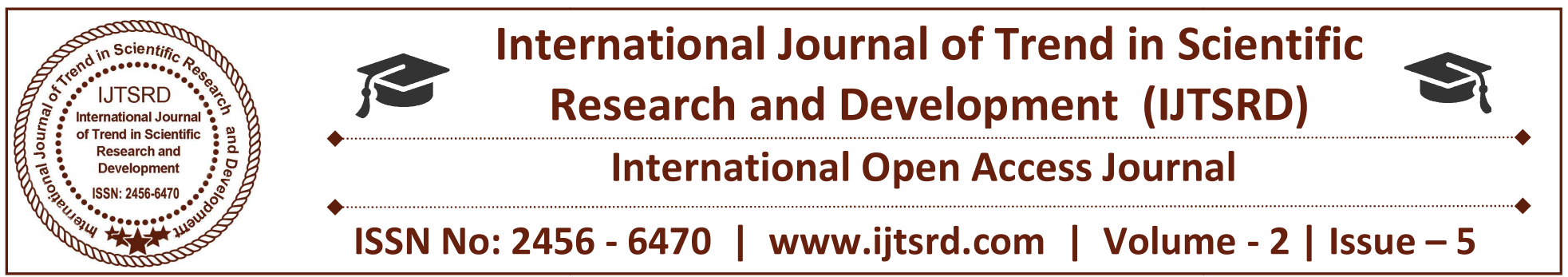

\title{
Optimization of a Composite Drive Shaft by Minimizaton of Sink Mark Defects in Injection Moulding Process
}

\author{
Ms. G Thasleema Nasreen ${ }^{1}$, Mr. N. Pavan Kumar ${ }^{2}$ \\ ${ }^{1}$ P. G. Scholar, ${ }^{2}$ Assistant Professor \\ Department of Mechanical Engineering, Sri Venkateswara Institute of Technology, \\ Anantapuramu, Andhra Pradesh, India
}

\begin{abstract}
The purpose of this paper is to present an integrated approach for improving the quality characteristics of the injection molded part (Honda Upper Part) being manufactured at manufacturing industry (Pakistan), where the rejection rate for Honda upper part was on ramp due to sink marks defects. The proposed integrated approach embraces the concept of Design of Experiments (Taguchi Approach) and Response surface design methodology for injection molding process optimization. The Taguchi Method (TM) was used to short list the variables that have significant effects on the sink marks in injection molded parts. Furthermore, the optimization approach of Response Surface Methodology (RSM) was utilized for the experimental research to acquire a prediction model that can be used to optimize injection molding process in terms of fine sink marks reduction. The result shows that the sink marks reduction
\end{abstract}

Predicted by the integration of the Taguchi Method and RSM indeed decreased from 0.0088 (Taguchi's result) down to $0.0080 \mathrm{~mm}$. The empirical results reveal that the integration of the Taguchi Method and RSM could effectively improve the quality. Basically with these experiments, we tried to open the vision of manufacturers and designers regarding the application of integrated RSM/Taguchi approach using linear cum interaction regression model with selected parametric/levels setting for the dimensional accuracy of the injection molded part, and thus contributing towards improvement in process's reliability. The integrated approach with regression model for optimization does not only provide theoretical worth to the literature and manufacturers/designers but can also be applied to different manufacturing industries for quality parts production.

KEYWORD: Q Injection Molding Process Optimization, Sink Marks, Design of Experiments, Taguchi Approach, Response Surface Methodology

\section{INTRODUCTION}

In the last 30 years, plastics have become the most dominant engineering material for most products. We take brief look at the most common types of plastics, and how they are processed.

Plastics has become the fundamental drivers of innovations and new product development. Uses of plastics are intertwined in every part of our contemporary life style, and have become indispensable; products made out of plastics range from sophisticated medical implants to disposable household implements. Intelligent and innovative use of plastics have opened up new avenues in the polymer-electronics sector; from organic light emitting diodes to electro-optical and bioelectrical complements, from low-cost plastics chips to flexible solar cells. Some of the plastics can conduct even electricity and emit light, leading to development of creative applications. Great popularity in use of plastics can be observed in automobiles and in a wide variety of industrial applications.

All plastics are polymers; these polymers are further divided into two basic types: thermoplastics and thermo sets. Thermoplastics melt when heated - so they can be melted and re-formed again and again. 
Thermo sets harden when they are heated, if heated further, they will break down chemically and lose their properties. Some thermo sets have properties very similar to rubber, and are used as synthetic rubber; they are categorized as elastomers. Here are some typical plastics and their uses:

\section{THERMO SETS}

General properties: more durable, harder, tough, light.

Typical uses: automobile parts, construction materials.

The most common methods of processing plastics to manufacture plastic parts are similar to methods we have learnt for metals and glass. These include Extrusion, Injection molding, Blow molding, Casting, etc. Among these, perhaps injection molding is the most significant for local industry - almost all manufacturing current trend of product development is towards lighter and smaller products yet it is expected to deliver powerful and effective solutions. Elegant and nice looking thin walled injection moulded enclosures and casings are in vogue. Focused attention on the issues of design and manufacturing processes can be seen from the proliferation of research activities. Substantial numbers of investigations have been reported on injection moulding process optimisation, in general, and quite a few on the sink marks, in particular. The investigations carried out in the last couple of decades were based on theoretical, FE flow simulation models and practical experimental trials. This section presents a detailed review of researches in the recent past on sink marks.

An early and notable study about shrinkage, warpage and sink marks was conducted by Chang and Tsaur (1995). Based on the rheological properties of polymers, an integrated theory and computer program was developed in this study for simulation of such behaviour. Hybrid finite-element and finite-difference methods were employed for simulating the injection moulding filling, packing, and cooling processes. A control volume method was applied towards both finding the melt front position and also calculating the temperature and pressure profile at any instant during the filling process. A modified Tait equation provides a description of the pressure-volume-temperature relationship of crystalline polymers. The Malkin's kinetics model was employed to describe the behavior of polymer crystallization. The flow-induced and thermal induced-residual stresses employed as the initial conditions in the solid mechanics analysis were obtained with the linear thermoviscoelastic model. The displacements, including the thickness. direction of part, which could not be calculated by the traditional bending moment method, were solved by using the numerical solid mechanics analysis with the three dimensional finite element methods. The theoretical results were also correlated using commercial FE flow simulation software. Though the integrated programme was able to simulate shrinkage and war page on moulded products, the sink simulation was not modelled conclusively

\section{METHODOLOGY}

Experimental set-up for conducting the simulation experiments consists of a suitable generic plastics part design, finite element model of the part, selection of a suitable grade of thermoplastics moulding material, an injection-moulding machine and a mould design details.

\subsection{D Part model}

Three Dimensional (3D) parametric part model is required as the basic input. The $3 \mathrm{D}$ part model can be generated from any CAD software capable of exporting options for simulation. In this case study, Honda Upper Part (product by Alsons Auto Pvt. Ltd.) was taken for experiments. The Sink marks was marked as one of the significant defect mostly occurred in molded Honda upper part causing many Manufacturing line rejection. The developed method was applied to the Injection molding process simulation of the Honda Upper Part housing. Simulation trials taken in such a way that to check how Sinks Marks defect changes as we change the parametric settings. The Honda upper part was designed using the CAD software. It was designed to its dimension according to the part drawing dimension data provided by the company. The part and its CAD design are shown in Figure-5. The optimization goal in the above study is the first point to be illuminated before initiating the analysis. The goal of the study is to determine the set of parameters which leads to the best part mold ability with lowest Sink Marks. The formulation of the goal leads to the identification of critical factors and the characterization of process performance variable. The feasible space for the molding parameters was defined in light of the data available in the literature, technical data sheets, and manufacturing expert's opinion. 


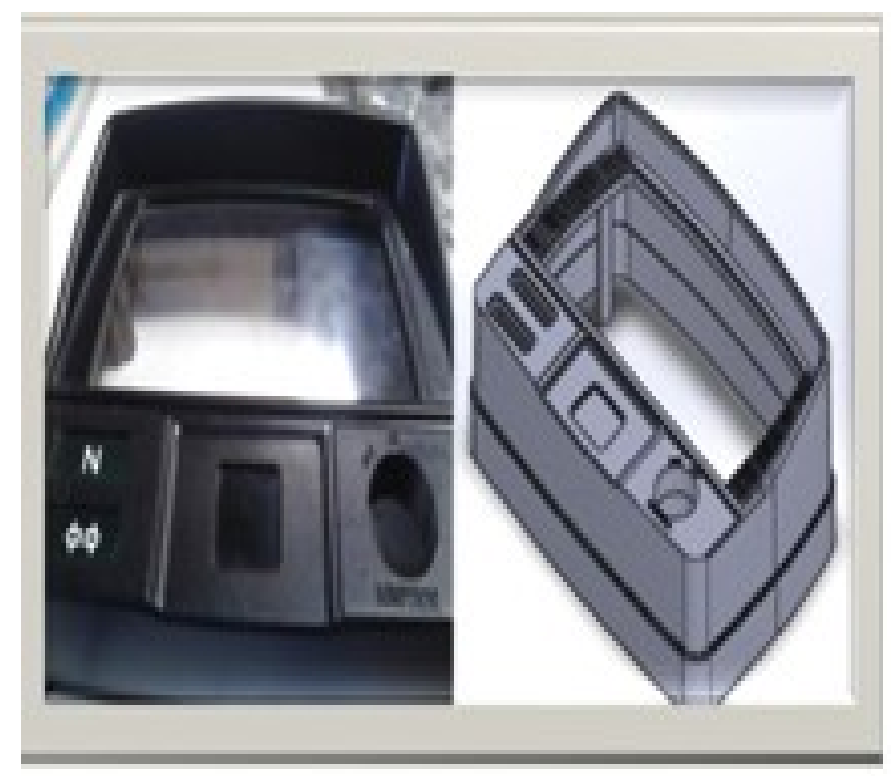

Figure 1:3D model

\section{RESULTS AND DISCUSSION}

\subsection{FE model for flow simulations}

In this present investigation Mold Flow, software is used for modelling the injection moulding process. Results of the FE flow simulation are quite sensitive to the data input to the programme. Important input data include a suitable model for creating FE mesh, the required processing data of the selected polymer and mould material specifications. The polymer data and the mould material specifications can be acquired from the material specification sheets. Using the standard procedure, a mid plane finite element model was created by meshing the 3D model with 1684 linear triangular shell elements. Average aspect ratio of the mesh used was 1.528. Mesh was thoroughly checked to eliminate mesh related errors. Feed system and cooling channels were created based on the mould design.

\subsection{Methods}

\section{Taguchi method}

A very useful DoE approach namely Taguchi's Quality function that maximizes the investigated process parameter space through minimal number of experiments. Taguchi's approach to quality control applies to the entire process of developing and manufacturing a product from initial concept $c$ to manufacturing/production in computer integrated manufacturing environment. Taguchi's method is a systematic application of design and analysis of experiments for the purpose of robust designing and improved quality. Taguchi achieves this objective by making the process insensitive to variations in output even though noise is present in the process as described by P-diagram (Figure-2). The process is then said to have become ROBUST (Y.P Tidke et al 2014).

The approach to optimization in Taguchi, for feasible and potential combinations of process parameters with parametric settings has the attractions for manufacturers and designers to implement in real time industrial applications. Taguchi parametric design approach has been utilized in past years for identifying the significant processing parameters and optimizing parametric setting. S. H. Tang et al. (2006) have analyzed thin plate for war page, while doing ANOVA using Taguchi's L9 orthogonal array. The authors screened out melt temperature, packing time and packing pressure as significant factors while filling time is insignificant towards war page defect. Feng, Chung et al. (2006) examined multiple

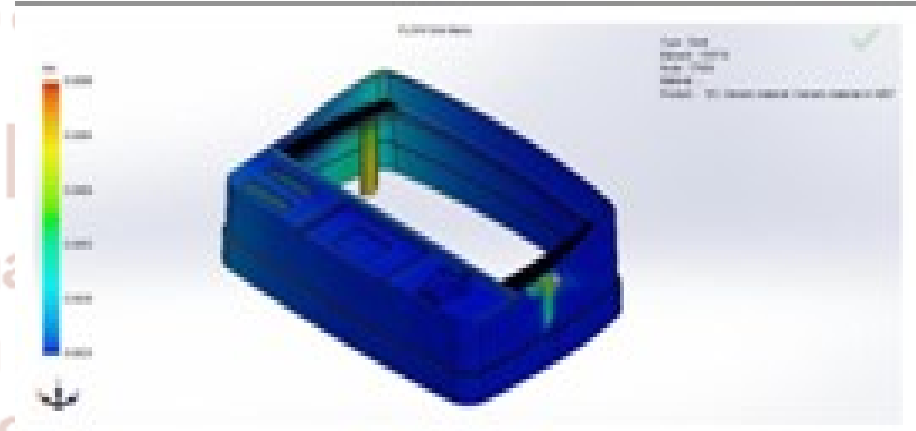

Fig2 3D model

\section{CONCLUSION}

This paper showed the effective integration of both optimizations tools for development of experimental models towards process optimization. The experimental design methods evade the experiential rules and Trial-and-Error methods that are traditionally used for improvement of part's quality. The experimental cost needed to achieve a robust, high-quality process, and improve the production throughput is also reduced. Following results were found:

The result shows that the optimization in terms of minimum sink marks obtained from integrated approach as 0.0080 , is better than the optimized figure of sink marks obtained with the Taguchi Method as stand alone. Three linear parameters (Mold Temperature, pressure Holding Time and filling time) and 01 interaction ( $\left(\mathrm{Mo}^{*} \mathrm{Ho}\right)$ have significant effect on minimum sink mark's optimization. The results also show that square terms between the parameters have insignificant effect on sink marks 


\section{REFERENCES}

1. Sanjay Lahoti, Prof M. D. Nadar, S. Kulkarni (2013) Optimization for Plastic Injection molding Process Parameters International Journal of Advanced Engineering Research and Studies EISSN2249-8974.

2. S. H. Tang, Y. J. Tan, S. M. Sapuan, S. Sulaiman, N. Ismail, R. Samin (2007). The use of Taguchi method in the design of plastic injection mould for reducing war page. Journal of Materials Processing Technology

3. B. Ozcelik and I. Sonat (2009). War page and Structural analysis of thin shell plastic in the plastic injection molding. Materials and Design

4. Mr. Aditya M. Darekar, Prof. T. S. Venkatesh, Dr. Bhushan T. Patil, Mr Yazad N. Doctor (2015). Review of Optimization Aspects for Plastic Injection Molding Process. IRACST Engineering Science and Technology: An International Journal (ESTIJ), ISSN: 2250-3498 Vol.5, No.1,

5. Feng, Chung; Jeffrey, Kuo; and Su, Te-Li. (2006), Optimization of Multiple Quality Characteristics for Polyether Ether Ketone Injection Molding Process, Fibers and Polymers, Vol.7, No.4, pp 404-41

6. Yung-TsanJou, Wen-Tsann Lin, Wei-Cheng Lee1 and Tsu-Ming Yeh(2014): "Integrating the Taguchi Method and Response Surface Methodology for Process Parameter Optimization of the Injection olding" Applied Mathematics \& Information Sciences An International JournalAppl. Math. Inf. Sci. 8, No. 3, 1277-1285

7. M. Aravind and Dr. S. Periyasamy (2014) "Optimization of Surface Grinding Process Parameters by Taguchi Method and Response Surface Methodology" International Journal of Engineering Research \& Technology (IJERT) ISSN: 2278-0181, Vol. 3 Issue 5,

8. Jae-Seob Kwak (2005), "Application of Taguchi and response surface methodologies for geometric error in surface grinding process", International Journal of Machine Tools \& Manufacture 45 (2005) 327-334, vol 45, pp.327-334.

9. L. M. Galantucci and R. Spina (2003), "Evaluation of filling conditions of injection moulding by integrating numerical simulations and experimental tests," Journal of materials processing technology, Vol. 141, no. 2, pp. 266275.

10. M. N. Dhavlikara, M. S. Kulkarnib, V. Mariappanc, (2003) "Combined Taguchi and dual response method for optimization of a centerless grinding operation", Journal of Materials Processing Technology, vol 321, pp.90- 94.

11. A. O. Andrisano (a), F. Gherardini (a), F. Leali (a), M. Pellicciari (a), A. Vergnano (2011), Design of Simulation Experiments method for Injection Molding process optimization

12. D. Mathivanan1, M. Nouby and R. Vidhya, (2010) "Minimization of sink mark defects in injection molding process - Taguchi approach," International Journal of Engineering, Science and Technology Vol. 2, No. 2, pp. 13-22.

13. Chen, W. C., M. W. Wang, G. L. Fu and C. T. Chen (2008), "Optimization of plastic injection molding process via Taguchi's parameter design method, BPNN, and DFP," International Conference on Machine Learning and Cybernetics, IEEE, vol. 6, pp. 3315-3321.

14. Babur Ozcelik (2011) "Optimization of injection parameters for mechanical properties of specimens with weld line of polypropylene using Taguchi method, "International Communications in Heat and Mass Transfer, Vol. 38, No. 8, pp. 1067-1072.

15. Z. Shayfull, M. Fathullah, S. Sharif, S. M. Nasir and N. A. Shuaib (2011), "War page Analysis on Ultra-Thin Shell by Using Taguchi Method and Analysis of Variance (ANOVA) for Three-Plate Mold," International Review of Mechanical Engineering (I.RE.M.E.), Vol. 5, no. 6, pp. 11161124.

16. S. M. Nasir, N. A. Shuaib, Z. Shayfull, M. Fathullah and R. Hamidon, (2011) "War page analysis on thin plate by taguchi method and analysis of variance (ANOVA) for PC, PC/ABS and ABS materials," International Review of Mechanical Engineering (I.RE.M.E.), Vol. 5, no. 6, pp. 1125-1131

17. Amit Kumar, Manojkumar Gaur, Dinesh Kumar Kasdekar and Sharad Agrawal, (2015) "TimeBased Optimization of Injection Moulding Process Using Response Surface Methodology" European Journal of Advances in Engineering and Technology, 2(5): 97-102. 
International Journal of Trend in Scientific Research and Development (IJTSRD) ISSN: 2456-6470

18. B. Sha, S. Dimov, C. Griffiths and M. Packianather (2007) "Investigation of microinjection moulding: Factors affecting the replication quality," Journal of Materials Processing Technology, vol. 183, pp. 284-296.

19. A. O. Andrisano (a), F. Gherardini (a), F. Leali (a), M. Pellicciari (a), A. Vergnano (2011) Design Of Simulation Experiments method for Injection Molding process optimization" Proceedings of the
IMProVe 2011 International conference on Innovative Methods in Product Design June 15th17th, 2011, Venice, Italy.

20. K.-T. Chiang and F.-P. Chang. (2007) Analysis of shrinkage and war page in an injection-molded part with a thin shell feature using the response surface methodology. International Journal of Advanced Manufacturing Technology 35 pp 468479. 